\title{
THE IMPORTANCE OF ENVIRONMENTAL SAFETY IN THE APPLICATION OF THE CONCEPT OF SMART TOURIST DESTINATIONS
}

\author{
Dejan Mandić, \\ Miloš Tomušilović, \\ Mesud Adžemović
}

Singidunum University, Belgrade, Serbia

\begin{abstract}
:
When the development of tourism is based on the principles of sustainable development it also contains a segment of environmental safety, because the concept of sustainable tourism is unattainable if the environmental safety indicators are not characterized in the right way. The smart tourist destination concept is based on the widespread use of advanced technologies and all types of data to improve overall destination management, and thus its prominence and competitiveness. Problems that have arisen in the environment, as a consequence of anthropogenic actions, have conditioned a different understanding of safety and the connection of environmental issues and safety. Environmental protection is an unavoidable factor of internal stability and safety, and the problems of endangering the environment are not only problems of internal, but also of global safety. Environmental safety refers to the relative safety of the public from environmental hazards caused by natural or human activity, environmental incidents, poor management or causes located within or outside national borders. Comparative indicators of sustainable tourism integrate indicators of environmental safety as a kind of warning indicators that provide a picture of the state of the environment and impacts that tourism has on certain media: water, air, biodiversity, soil.
\end{abstract}

Keywords:

environmental safety, indicators, smart tourist destination, sustainable tourism.

\section{INTRODUCTION}

The modern age, with all its continuous challenges arising from numerous factors and interests, demands new approaches that would from a theoretical point of view provide adequate answers to the "open" questions posed by the modern age.

Tourism, which depicts society and monitors changes in the habits, behaving, tendencies and psychological inclinations of the entire population, imposes itself as an important factor in preserving the environment and all those resources that are essential for its development and long-term survival. In this regard, there is a need for all stakeholders to act in accordance with the principles and goals of sustainable development, recognizing and understanding the role of the tourism sector in preserving the environment, whose disruption and degradation raise risks, not only in terms of internal stability, but security at the global level. 
The need to transform and adapt tourism to socially and environmentally responsible activity, with an emphasis on planning and implementing sustainable development strategies, is becoming an imperative of modern times. One of the desired consequences of this transformation is reflected through the prism of the phenomenon of sustainable tourism, with the goal for its principles to be fundamentally rooted in the tourism itself, to avoid the scenario that sustainable tourism remains vague and does not recognize the principles and values of eco-tourism.

Analysis of the current situation and close perception of the future has imposed the need to develop a strategy for sustainable tourism development, where the traditional perception of cities and tourist destinations must necessarily be transformed by a new perception, i.e. dimension that is by definition smart. "Smart" means the unbothered functioning of entities through the improvement of experiences through the use of new technologies and innovations, which serve as support for all those activities directed at preserving the environment, and together they accepted the values that will create an adequate basis to achieve and establish a true principle of tourism sustainability.

\section{SUSTAINABLE TOURISM AND ENVIRONMENT}

The relation between tourism and the environment cannot be viewed as an equal set of influences concerning the relation between the presence and the entities. The long-term survival of its business tourism bases on availability. This availability, in addition to exploitation and use by economic and other activities, can be linked to tourism. When we talk about the nature of these influences, it is possible to single out direct influences, such as deforestation for the purpose of building hotel capacities, but also indirect impacts, such as impact of noise on wildlife.

Tourism is a complex activity that involves significant financial resources and economic incentives for environmental protection, restoration of buildings of historical importance and preservation of local customs, traditions and cultures. Tourism also contributes to understanding among people of different cultures and, perhaps most obviously, provides an "escape" from the stress and routine of everyday life (Theobald, 2005).

The impacts of tourism on the environment and resources can be seen through three categories: economic impacts, socio-cultural and spatial-environmental, each of these categories include positive and negative impacts. The impacts are different because the resources, conditions and levels of tourism development are different and specific. The concept of mass tourism is dominated by the economic approach in tourism development planning, and success is evaluated exclusively by economic indicators. By moving away from that concept, it tends to advocate for sustainable tourism development. Participants at the local level must reach for the arsenal of visionary approaches and consistently consider the possibilities and interests of all community members, so that the positive impacts of tourism outweigh the negative ones that need to be reduced to an absolute minimum (Milošević, 2009).

The environment is an organic unity of the atmosphere, hydrosphere, pedosphere, biosphere and environmental media: air, water and soil. The development of tourism, if not controlled, can have negative consequences for all segments of the environment, in a direct and indirect way (Dražić, 2020).

Every form of tourism can be sustainable if it uses the resources on which its future depends in the short and long term in a responsible and rational way. The condition and imperative requirement for the development of sustainable tourism, which is closely related to water resources, for example, is the observance of rigorous standards for preserving water quality. In that sense, an important element is the protection of the environment, or at least the absence of negative influences (Božić and Milošević, 2019).

Sustainable development implies both economic and social sustainability. Social sustainability is closely related to local communities, their traditions and culture, which remains consistent and whose integrity is actually strengthened, although under the influence of other cultures that tourists "bring" from their home places. Economic sustainability ensures the long-term survival of tourism through the generation of economic growth that serves to finance protection and enables sustainable use of resources (Beljanski, 2018).

The wide availability of attractive destinations has influenced the massiveness of tourist movements under the expansion of tourist demand. Ecological sustainability enables development in accordance with ecological 
processes and biological diversity. Social and cultural sustainability means harmonizing the development of tourism with the traditional values of local communities, while economic sustainability ensures long-term economic efficiency. All three of these principles insist on conserving resources (Marković et al., 2016).

The principles of sustainable tourism can be classified as follows (Fig.1):

- Sustainable use of resources - the emphasis is on the preservation and sustainable use of natural, social and cultural resources;

- Reduction of waste and excessive consumption of resources - thus minimizing the negative impact on the environment and achieving economy in terms of funds needed to invest in protection and damage remediation;

- Maintaining biodiversity - it is a key resource for tourism and its protection and promotion ensures long-term survival and development;

- Inclusion of tourism in development plans - tourism will ensure its long-term sustainability if it is an integral part of local, regional and national development plans;

- Contribution to the local economy - sustainability includes the return of a certain percentage of income from tourism, which will be used to finance environmental protection and direct investment in tourism resources;

- Involvement of local participants - it is not possible to have satisfied tourists if the local population is not satisfied with the presence and activities of tourists, so the involvement of local participants is an important step in planning the development of tourism in a destination;

- Consulting participants and the public - on any question related to the environment, i.e. natural, social and cultural resources, it is necessary to consult as many participants as possible;

- Training of staff - it is crucial to conduct a comprehensive education of staff on current issues of sustainable development and management, which will result in a higher quality tourist product and satisfied visitors. Not only tourism experts are responsible for managing the sustainable development of tourism, but also ecologists and geographers, economists and marketing experts;

- Responsible marketing - which is based on ethical principles and moral values, is a useful tool in managing the tourism of a particular destination. The more information is shared with tourists, the greater their sense of responsibility in relation to natural, social and cultural resources;

- Market research (emitting and receptive) - it is not possible to survive and thrive in the tourism market without continuous collection, processing and analysis of all relevant data concerning the sustainable management of the tourist destination. The strategy of tourist destination management is adjusted to the requirements, wishes and preferences of tourist demand.

Figure 1. Principles and goals of sustainable tourism

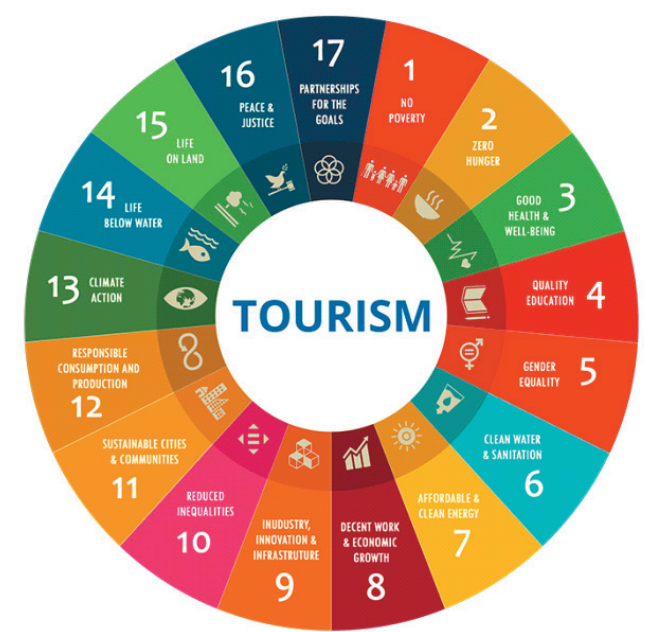


Ecotourism is a responsible tourism because it actively minimizes the negative consequences on the environment, while strengthening the local culture and tradition. Ecotourism promotes the medical moment as an integral part of eco-products and implies the active participation of tourists in sports and recreational activities such as hiking, mountaineering, cycling and swimming. This form of tourism has determined as a target group ecologically conscious tourists who see the preservation of the environment as a priority of modern civilization and are willing to pay a price for practicing this form of tourism which is increased by a symbolic amount. Free time is becoming more valuable, so tourists want to spend it in destinations characterized by clean sea, unpolluted rivers, preserved flora and fauna, clean air and healthy food. An important aspect of ecotourism, which is also characterized by the connection with rural tourism, is the spatial protection of nature, especially those parts of it that are important for scientific, cultural-educational and recreational purposes (Čekrlija, 2017).

\section{INDICATORS OF ENVIRONMENTAL SAFETY}

When the development of tourism is based on the principles of sustainable development, it unequivocally contains the segment of ecological safety because the concept of sustainable tourism is unattainable if the indicators of ecological safety are not characterized in the right way. Problems that have arisen in the environment as a consequence of anthropogenic action, have conditioned a different understanding of safety and the connection between environmental problems and safety. The connection between the environment and war conflicts was pointed out through "research on environmental and security topics related to global environmental changes, ecological scarcity, degradation and stress, as well as their possible socio-political consequences." In that sense, it is pointed out that preserving the environment is an unavoidable factor of internal stability and security of a country, but also that the problem of endangering the environment is not only a problem of internal, but also security at the global level (Adžemovic, 2019).

Ecological safety also refers to the safety of the public from ecological hazards, as a result of ignorance, incidents, poor management, poor design or causes located within or outside national borders. Ecological safety is also solving the problem of insufficient resources, environmental degradation and biological hazards, and methods of overcoming these problems include the use of ecologically valid technologies (use of renewable resources, recycling, less waste), as well as the application of legal and economic instruments of environmental protection (Adžemovic, 2019).

Indicators of ecological safety, which should facilitate and guarantee the quality of life, can be classified into several clusters, such as: legal norms in the field of the environment; regulations governing the field of environment; implemented environmental protection programs; spent funds for environmental protection; but also indicators related to air (climate change, ozone depletion), water (reduction of surface and groundwater levels), soil (acidification and soil degradation), biodiversity (loss of biodiversity) and forests (forest degradation). Problems that can be related to the quality of water, air and land are urban stress, major ecological incidents (industrial processes, natural disasters), population growth, unsustainable consumption and loss of natural resources (Adžemovic, 2019).

\section{DISCUSSION -SMART TOURIST DESTINATIONS}

Just as it was logical to expect tourism to respond to the principles of sustainable development with its version of sustainable tourism, nothing less is expected of tourism economy activities to implement the phenomenon of smart cities into their destination management.

It would be wrong to link smart tourism exclusively to its ecological aspect, although one of the more important goals of smart tourism relates to the effects of tourism decisions on the environment. It implies something much broader and more complex, and is based on the use of information and communication technologies. However, it is not possible to implement the element of smartness in tourist destinations and make them smart destinations if the mentioned elements are not previously incorporated into the phenomenon of tourism, making it smart tourism. 
To understand the concept of smart tourism, it is necessary to look at the traditional concept of tourism, enriched by the use of smart technologies and innovations. When it comes to smartness, we start from information, all with the aim of innovation in terms of designing tourism products and securing a competitive position in a dynamic market, as well as improving the tourist experience of visitors and more efficient business in terms of resource use, in order for "smartness" to provide a stronger foundation for sustainable tourism.

The smart tourist destination is based on the widespread use of advanced technologies with the goal of creating an integrated digital space and improving competitiveness (Fig. 2). The smart tourist destination promotes innovative values, quality of services and original values of the local community (Vargas-Sanchez, 2016).

When developing conceptual models of smart tourist destinations, we start from precisely defined key issues and criteria by which their strength, position and competitiveness is determined (Koo et al., 2016). Among the most important are the issues of optimal relationship and rational use of natural resources for tourism purposes, but also what are the decisive factors and criteria on the basis of which a smart destination is characterized and represented.

Three types of information and communication technologies can be identified as key for the application of the concept of smart tourist destinations, i.e. for their establishment:

1. Cloud computing - this technology provides access to web platforms and data stored on the cloud via a specific network. In the context of a smart tourist destination, that would mean sophisticated systems of digital tourist guides, which would be on the so-called cloud, without the need for visitors to download them to their own devices;

2. Internet of Things (IoT, the interconnection of computer devices embedded in everyday objects via the Internet, allows them to send and receive data) - in the context of tourism, it could provide information and analysis, as well as control (chips embedded in tickets of certain attractions provide insight into the consumption of visitors and insight into the popularity of certain segments within the attraction based on location analysis). On the other hand, if we are talking about control, it is possible to control the flow of tourists through sensors and thus take care not to break through the carrying capacity of the site or attraction;

3. End-user internet service system - means applications at different levels, supported by a combination of cloud computing and Internet of Things, e.g. an innovative hub for electric vehicles, and the app contains charging point maps and provides real-time information on vacancies and their locations (Buhalis and Amaranggana, 2015).

Figure 2. Use of informationand communication technologies in destination management

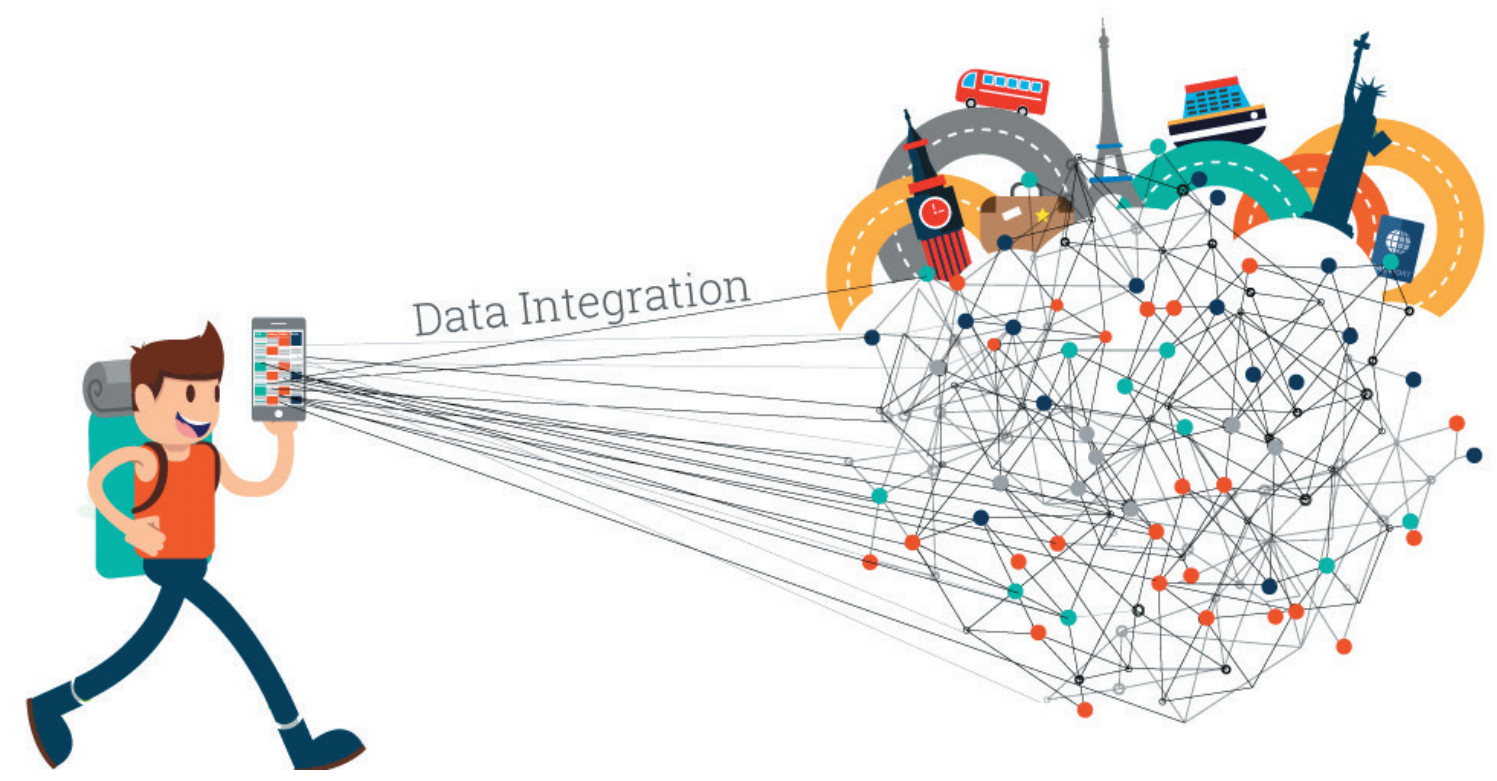

Source: www.ontotext.com, 2016 


\section{CONCLUSION}

The research that covered the practical application of smart technologies and innovations in the business of entities in Subotica (Gallery Hotel, Zvonko Bogdan Winery, Contemporary Gallery Subotica -RajhelovaPalata and Zvonko Bogdan Farm Winery), which meet the needs of tourist demand for their services, on the one hand the efficiency of the mentioned approach, while on the other hand the degree of progress and innovation in relation to modern standards has been determined.

The applicability of smart technologies and innovations in tourism has proven to be an indispensable part of all future plans for the development of this activity, mostly because the mentioned technologies are in line with the transformation of tourism that strives for sustainability, and enable equal commitment to all elements of sustainability, for cost-effectiveness and success of tourism activities.

Smart technologies and innovations can also be seen as a basic or digital infrastructure for implementing the concept of smart cities, or in this case smart tourist destinations. However, in societies that have not reached the full level of implementation, progress is recognized by the level of smart technologies and innovations applied in the everyday life of the city or destination. The concept is a higher level and does not only mean "smartness" engraved in all city services and elements, but also harmonization and synchronized functioning.

The research identified the implementation and use of smart technologies and innovations that precede the concept, determining the level of implementation with suggestions for better use of available technologies. The fact is that it is difficult to determine the exact level of distance from the implementation of the concept of smart cities and destinations, because the results are revealed much later, preceded by years of research, planning, forming partnerships and establishing or harmonizing strategies. However, the positive effects that the concept entails with its implementation are clear, which means that there is no reason to stop only at the individual use of technologies and innovations, without a clear initiative to unite into a single system that harmoniously affects the well-being of its inhabitants.

On the other hand, the concept needs to be tested on smaller samples and if the implementation proves successful, scaling the project to wider and more complex systems is initiated. Therefore, it was expected that the original concepts would appear in smaller communities such as Subotica, before expanding to larger ones such as Novi Sad or Belgrade.

The paper also highlighted the link between tourism and the environment, primarily "dissecting" tourism into a chain of segments, which are then symbolically exposed to the elements of the environment affected by their uncontrolled development, and finally transformed by the use of modern technologies into segments that like puzzle pieces merge into a collective vision of sustainable tourism.

\section{REFERENCES}

Adžemović, M. (2019).Ecological safety.University Singidunum, pp. 6-26, Belgrade, Retrieved September $15^{\text {th }}$, 2020 from http://master.crnarupa.singidunum.ac.rs/2019-2020/Zivotna+sredina+i+odrzivi+razvoj/Ekoloska\%20 bezbednost\%20-\%20Mesud\%20Adzemovic/).

AlexandreGarrido Blog. (2020). Myth or true: Following safety protocols will transform tourism operations less sustainable. Retreived on September $15^{\text {th }}, 2020$ from https://turismosustentavel.blog.br/2020/10/27/ myth-or-true-following-safety-protocols-will-transform-tourism-operations-less-sustainable/

Beljanski, N. (2018). Ecological responsibility of tourism.TIMS Acta 12, 37-45, Novi Sad, DOI: https://doi.org/10.5937/timsact12-15846

Božić, A., Milošević, S. (2019). Ecological responsibility in the hotel industry. TIMSActa 13, 51-60, Novi Sad, DOI:10.5937/timsact13-20598

Buhalis, D., Amaranggana A. (2015). Smart Tourism Destinations Enhancing Tourism Experience Through Personalisation of Service, Springer International Publishing, pp. 377-389, Switzerland, DOI 10.1007/ 978-3-319-14343-9_28

Čekrlija, S. (2017). Ecotourism and sustainable resource management. "Svarog", 14. (227-235), Independent University Banja Luka, Banja Luka, DOI 10.7251/SVA1714227C 
Dražić, G. (2020). Sustainable tourism. University Singidunum, Faculty of Tourism and HotelManagement, Belgrade, Retrieved on September $15^{\text {th }}, 2020$ from https://singipedia.singidunum.ac.rs/izdanje/43277odrzivi-turizam.

Koo, C., Shin, S., Gretzel, U., Cannon Hunter, W., Chung, N. (2016). Conceptualization Of Smart Tourism Destination Competitiveness. Asia Pacific Journal of Information Systems, Vol. 26 No. 4, 561-576, http:// dx.doi.org/10.14329/apjis.2016.26.4.561

Marković, S., Perić, M., \& Mijatov, M. (2016).Application of comparative EU indicators: The city of Uzice case study (Serbia).Journal of the Geographical Institute" Jovan Cvijic", SASA, 66(2), 255-271. DOI: 10.2298/ IJGI1602255M.

Milošević, M. (2009). Impacts of tourism on the quality of the environment in Europe (Bechelor's thesis), Faculty of Tourism and Hotel Management, UniversitySingidunum, pp. 10-16, Belgrade.

Ontotext. (2016).Linked Data Paths To A Smart Tourism Journey. Retrieved September 15 ${ }^{\text {th }}, 2020$ from https:// www.ontotext.com/blog/linked-data-paths-smart-tourism-journey/

Theobald, W. (2005).Global Tourism-Third Edition. Elsevier Inc., pp. 33-52, Amsterdam,Netherlands, ISBN: 0-7506-7789-9.

Vargas-Sanchez, A. (2016). Exploring the concept of smart tourist destination. Enlightening Tourism,A Pathmaking Journal, Vol 6, No 2, pp. 178-196, ISSN 2174-548X, Retrieved September 15 $5^{\text {th}}, 2020$ from https://www.academia.edu/30399422/EXPLORING_THE_CONCEPT_OF_SMART_TOURIST_DESTINATION 